\title{
Direct and indirect costs and cost-driving factors of Tuberous sclerosis complex in children, adolescents, and caregivers: a multicenter cohort study
}

Janina Grau ${ }^{1,2}$, Johann Philipp Zöllner ${ }^{1,2}$, Susanne Schubert-Bast ${ }^{1,2,3}$, Gerhard Kurlemann ${ }^{4}$, Christoph Hertzberg ${ }^{5}$, Adelheid Wiemer-Kruel ${ }^{6}$, Thomas Bast ${ }^{6}$, Astrid Bertsche $^{7}$, Ulrich Bettendorf ${ }^{8}$, Barbara Fiedler ${ }^{9}$, Andreas Hahn ${ }^{10}$, Hans Hartmann ${ }^{11}$, Frauke Hornemann ${ }^{12}$, Ilka Immisch ${ }^{13}$, Julia Jacobs ${ }^{14,15}$, Matthias Kieslich 1,3, Karl Martin Klein 1,2,16, Kerstin A. Klotz ${ }^{14,17}$, Gerhard Kluger ${ }^{18,19}$, Markus Knuf20,21, Thomas Mayer ${ }^{22}$, Klaus Marquard ${ }^{23}$, Sascha Meyer ${ }^{24}$, Hiltrud Muhle ${ }^{25}$, Karen Müller-Schlüter ${ }^{26}$, Anna H. Noda ${ }^{1,2}$, Susanne Ruf ${ }^{27}$, Matthias Sauter ${ }^{28}$, Jan-Ulrich Schlump ${ }^{29}$, Steffen Syrbe ${ }^{30}$, Charlotte Thiels ${ }^{31}$, Regina Trollmann ${ }^{32}$, Bernd Wilken ${ }^{33}$, Laurent M. Willems ${ }^{1,2}$, Felix Rosenow ${ }^{1,2}$ and Adam Strzelczyk ${ }^{1,2,13^{*}}$ (D)

\begin{abstract}
Background: Tuberous sclerosis complex (TSC), a multisystem genetic disorder, affects many organs and systems, characterized by benign growths. This German multicenter study estimated the disease-specific costs and cost-driving factors associated with various organ manifestations in TSC patients.

Methods: A validated, three-month, retrospective questionnaire was administered to assess the sociodemographic and clinical characteristics, organ manifestations, direct, indirect, out-of-pocket, and nursing care-level costs, completed by caregivers of patients with TSC throughout Germany.
\end{abstract}

Results: The caregivers of 184 patients (mean age $9.8 \pm 5.3$ years, range $0.7-21.8$ years) submitted questionnaires. The reported TSC disease manifestations included epilepsy (92\%), skin disorders (86\%), structural brain disorders (83\%), heart and circulatory system disorders (67\%), kidney and urinary tract disorders (53\%), and psychiatric disorders (51\%). Genetic variations in TSC2 were reported in $46 \%$ of patients, whereas $14 \%$ were reported in TSC1. Mean total direct health care costs were EUR 4949 [95\% confidence interval (95\% CI) EUR 4088-5863, median EUR 2062] per patient over three months. Medication costs represented the largest direct cost category ( $54 \%$ of total direct costs, mean EUR 2658), with mechanistic target of rapamycin (mTOR) inhibitors representing the largest share (47\%, EUR 2309). The cost of anti-seizure drugs (ASDs) accounted for a mean of only EUR 260 (5\%). Inpatient costs (21\%, EUR 1027) and ancillary therapy costs (8\%, EUR 407) were also important direct cost components. The mean nursing care-level costs were EUR 1163 (95\% Cl EUR 1027-1314, median EUR 1635) over three months. Total indirect costs totaled a mean of EUR 2813 (95\% CI EUR 2221-3394, median EUR 215) for mothers and EUR 372 (95\% CI EUR 193-586, median EUR 0) for

\footnotetext{
*Correspondence: strzelczyk@med.uni-frankfurt.de

${ }^{1}$ Epilepsy Center Frankfurt Rhine-Main and Department of Neurology,

Goethe-University Frankfurt, Schleusenweg 2-16 (Haus 95),

60528 Frankfurt am Main, Germany

Full list of author information is available at the end of the article
}

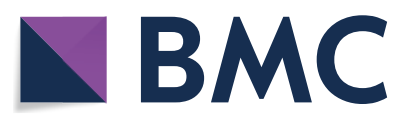

(c) The Author(s) 2021. Open Access This article is licensed under a Creative Commons Attribution 4.0 International License, which permits use, sharing, adaptation, distribution and reproduction in any medium or format, as long as you give appropriate credit to the original author(s) and the source, provide a link to the Creative Commons licence, and indicate if changes were made. The images or other third party material in this article are included in the article's Creative Commons licence, unless indicated otherwise in a credit line to the material. If material is not included in the article's Creative Commons licence and your intended use is not permitted by statutory regulation or exceeds the permitted use, you will need to obtain permission directly from the copyright holder. To view a copy of this licence, visit http://creativecommons.org/licenses/by/4.0/. The Creative Commons Public Domain Dedication waiver (http://creativeco mmons.org/publicdomain/zero/1.0/) applies to the data made available in this article, unless otherwise stated in a credit line to the data. 
fathers. Multiple regression analyses revealed polytherapy with two or more ASDs and the use of mTOR inhibitors as independent cost-driving factors of total direct costs. Disability and psychiatric disease were independent cost-driving factors for total indirect costs as well as for nursing care-level costs.

Conclusions: This study revealed substantial direct (including medication), nursing care-level, and indirect costs associated with TSC over three months, highlighting the spectrum of organ manifestations and their treatment needs in the German healthcare setting.

Trial registration: DRKS, DRKS00016045. Registered 01 March 2019, http://www.drks.de/DRKS00016045.

Keywords: mTOR inhibitor, Everolimus, Seizure, Rhabdomyoma, Epilepsy, Anti-seizure medication

\section{Key Point}

- First study to measure both direct and indirect costs of children with TSC and their caregivers.

- Mean total direct costs were estimated to be EUR 4949 for three months.

- Medication, especially mTOR inhibitors, and hospitalization are major direct cost components.

- Total indirect costs were higher for mothers (mean EUR 2813 for three months) than fathers (EUR 372).

- Total costs are driven by the number of TSC manifestations and affected organ systems.

\section{Background}

Tuberous sclerosis complex (TSC) is a rare, multisystem, genetic disorder that affects up to 1 in 5,000 individuals worldwide. Until recently, the prevalence of TSC was underestimated due to incomplete penetrance and considerable inter-individual phenotypic variability among those affected by TSC [1-6]. The clinical manifestation of TSC undergoes a typical pattern of changes during life, in which multiple organs and systems are affected, leading to the development of typically benign tumors that present preferentially in the skin, brain, and kidneys. Most individuals with TSC suffer from structural epilepsy due to the presence of cortical tubers or other cortical malformations. The clinical picture may differ considerably among patients and range from very limited manifestations to severe impairments, requiring nursing assistance $[3,7]$.

TSC is caused by a loss of function mutation in one of two tumor suppressor genes, TSC1 or TSC2 (ratio 1:3.4, as reported in [8]), and is inherited in an autosomal-dominant fashion; however, the majority of cases appear to be caused by de novo mutations. Genetic mosaicism and deep intronic mutations may contribute to disease development in the $15 \%$ of cases associated with no definitive hereditary mutation, despite a definite clinical diagnosis of TSC [8]. Loss of function mutations in TSC1 or TSC2 result in deregulated expression patterns for components of the mechanistic target of rapamycin (mTOR) pathway, resulting in the abnormal production of end products, which ultimately promotes tumorigenesis [9]. Treatment with mTOR inhibitors addresses the underlying cause and might prevent epileptogenesis and late organ manifestations [10].

The burden of illness in TSC is considerable and directly associated with the complex and multifaceted disease manifestations [11-15]. Several studies examining the cost-of-illness (COI) and their predictors in TSC have been published over the last two decades; however, only a few have addressed both direct costs and cost-driving factors, and the indirect costs experienced by the caregivers of children with TSC have not yet been addressed [3]. Furthermore, the majority of available studies evaluated patients before the availability of mTOR inhibitors, such as everolimus, which has been approved for the treatment of various organ manifestations in TSC $[3,16]$.

Thus, the present study aimed to provide a comprehensive analysis of the direct and indirect costs and potential cost-driving factors among a large, multicenter cohort of children, adolescents, and their caregivers in Germany.

\section{Methods}

\section{Patients and recruitment}

This study was designed as a cross-sectional, multicenter survey, which enrolled patients with TSC and their caregivers through the German TSC patient advocacy group (Tuberöse Sklerose Deutschland e.V., Wiesbaden, Germany) and from centers throughout Germany (Berlin, Bochum, Dresden [Radeberg], Erlangen, Frankfurt, Freiburg, Giessen, Hannover, Herdecke, Heidelberg, Hirschaid, Homburg, Kassel, Kiel, Kork, Leipzig, Lingen, Marburg, Münster, Neuruppin, Oberhausen, Rostock, Stuttgart, Tübingen, Vogtareuth, and Wiesbaden). 


\section{Survey methods}

After receiving written informed consent from the patients' parents or legal guardians, all patients with TSC and their caregivers were deemed eligible. The diagnostic criteria for TSC were based on the latest recommendations, which were established by the 2012 International TSC Consensus Conference [17]. Seven primary manifestation categories associated with TSC were identified, including epilepsy, structural brain disorders, psychiatric disorders, heart/circulatory system disorders, kidney and urinary tract disorders, skin disorders, respiratory system disorders, and other manifestations [11]. The seizure and epilepsy syndrome classifications were adapted according to the latest definitions established by the International League Against Epilepsy (ILAE) [18, 19]. This study received ethics approval and was registered with the German Clinical Trials Register (DRKS00016045; Universal Trial Number: U1111-1229-4714). The STROBE guidelines (Strengthening The Reporting of Observational Studies in Epidemiology) were closely followed [20].

The caregivers of patients with TSC were asked to complete a retrospective questionnaire referencing the previous three months. The questionnaire, which was validated in previous studies [21-23] and adapted for use in patients with TSC, comprised 36 questions regarding disease characteristics (e.g., genetics, affected organ systems, seizure occurrence, medication use, and additional symptoms), healthcare resource use (e.g., healthcare visits, accidents, and emergency care), and social conditions. Paper questionnaires were mailed to caregivers in Germany between February and July 2019.

\section{Costing methods}

The aim of this study was to calculate the genuine costs associated directly with TSC, rather than the costs associated with conditions other than TSC. Therefore, caregivers were asked, in detail, whether the medications, services, and other medical resources used were specifically associated with TSC organ manifestations. Costs were evaluated through a bottom-up approach from the perspective of the statutory health insurer ("Gesetzliche Krankenversicherung" [GKV]), the patients and society as a whole. The cost categories that were included in this analysis included direct health service costs covered by the statutory health insurance and as patients' and caregivers' out-of-pocket (OOP) expenses, nursing carelevel costs covered by the statutory care insurance, and further informal care not covered by any statutory insurance, and indirect costs. Costs were evaluated according to the German recommendations for performing economic evaluations related to healthcare [24].

\section{Direct healthcare costs}

Direct health service costs, which included inpatient stays, outpatient visits, medicines [anti-seizure drugs (ASDs), mTOR inhibitors, other prescription drugs, overthe-counter drugs, and emergency medications], medical aids, healthcare professional visits, emergency transportation, diagnostic studies, specific diets, patients' co-payments, rehabilitation costs, private transport costs, and co-payments for therapies, were drawn from the literature and standard reference sources for Germany and were estimated as previously described [21, 25]. Drug costs were based on the Drug Prescription Report of 2019 ("Arzneiverordnungs-Report") [26], which is an index of available medicines and their average prices in Germany. The costs of inpatient and outpatient care, specialist care, therapies, and diagnostic studies were standardized, according to Bock et al. [27] and physician fee scales (Einheitlicher Bewertungsmaßstab) [28]. All costs were inflated to 2019 levels using the consumer price index for Germany and expressed in both annual and 3-month terms based on the 2019 value of the Euro.

\section{Out-of-pocket (OOP) expenses}

OOP expenses (co-payments) were reported by respondents. For situations in which supply-side utilization estimates were not available (care and supervision, healing agents, and diets), and for those expenditures outside of formal healthcare settings (alternative and occupational therapies and equipment costs), the reported costs were listed as OOP expenses and added to total direct healthcare costs. For instances in which supply-side cost estimates were calculated according to resource utilization (ancillary treatments, medical aids, healthcare professionals, and emergency transportation), OOP expenses were considered to be accounted for, and were not added to total direct costs to prevent double accounting.

\section{Nursing care-level costs and grade of disability}

In Germany, care insurance payments are determined by the patient care grade, which ranges from Level 1 to 5 on the Pflegegrade scale (which categorizes the need for care), and determines the basis for the care allowances that are paid by the German statutory care insurance "Pflegeversicherung" [29]. Care grade levels depend on the time needed per day in minutes for care in daily life. Average care grade allowances were calculated based on the assumption that nursing services were being provided 
by family members. Nursing care-level costs in this study may be interpreted as a proxy for overall informal care costs. Additional informal care costs that were reported and paid by the respondents were considered separately.

The "grade of disability" is assigned in the German social system to people with disabilities who are entitled to certain monetary and social compensations for their disadvantages. The grade of disability quantifies the type and severity of a disability, upon which these compensations depend. Grade of disability is classified by an independent medical professional ("Versorgungsamt") and if applicable can vary between 20 and 100, in steps of ten.

\section{Indirect costs}

Productivity losses associated with the need to care for TSC patients were calculated for caregivers of working age (i.e., below the age of 67 years) using the human capital approach for days off, quitting work, and reductions in working hours. Productivity losses due to TSC among adolescent patients of working age (i.e., $>16$ years of age) were considered in terms of days off for working adolescents and the inability to work among those who were completely unable to work or attend school. A mean gross wage of EUR 44,964 in 2019 [30] was assumed for calculating the productivity costs for caregivers who quit their jobs. To account for the costs of days taken off work to care for a child with TSC, annual gross wages were calculated to represent EUR 215 per calendar day, and this daily income was multiplied by the number of days off [22].

\section{Grouping of questionnaire items}

Some questionnaire items were collated into groups when presenting the results, as follows: 'ancillary costs': physiotherapy, speech therapy, occupational therapy, acupuncture, hippotherapy, and other ancillary costs; 'healthcare professionals': neurologists, general practitioners, orthopedic surgeons, child psychiatrists, alternative medicine practitioners, homeopathy, dietitians, and other specialists; and 'diagnostic studies': electroencephalography (EEG), blood tests, magnetic resonance imaging (MRI) or computed tomography (CT) scans, X-rays, and other diagnostic studies.

\section{Data availability statement}

The reported data and the questionnaire are available to qualified researchers upon reasonable request.

\section{Statistical analysis}

Statistical analysis was performed using IBM SPSS Statistics, version 26 (IBM Corp., Armonk, NY, USA). The variables of interest were summarized using the mean, median, and standard deviation (SD). For cost data, the 95\% confidence interval $(95 \% \mathrm{CI})$ was calculated using the bootstrap-corrected and accelerated method, considering the fact that most cost variables are highly skewed [31]. Comparisons between groups were performed using adequate parametric and nonparametric tests. Significance was assumed at $p<0.05$. The relationship between patient characteristics and TSC-related costs was investigated using multivariate regression. Total direct, total indirect, and nursing care-level costs were regressed on a set of clinical variables that were selected following univariate analyses and according to evidence from previous cost-of-illness studies for TSC [11, 32, 33]. All variables were tested for interactions and collinearity. Standard multiple regression analysis using the bootstrapping technique was performed to identify independent predictors of costs, and a Bonferroni correction was applied for multiple testing.

\section{Results}

\section{Demographic and clinical characteristics}

One hundred and eighty-four caregivers of children and adolescents with TSC completed the questionnaire. The mean patient age was 9.8 years (SD 5.3 years, median 9.8 years; range $0.7-21.8$ years), and $48.4 \%(n=89)$ of patients were females. TSC was diagnosed at a mean age of 1.3 years (SD 2.1 years, median 0.5 years; range $0-12.1$ years), and the first symptoms of TSC were observed at a mean age of 0.8 years (SD 1.3 years, median 0.4 years; range $0-7.7$ years). In 34 children (18.5\%), a diagnosis of TSC was suspected before birth based on the findings of ultrasound examinations. In 25 patients (13.6\%), variations were identified in TSC1, whereas in 85 patients $(46.2 \%)$, variations were observed in TSC2 (TSC1:TSC2 ratio 1:3.4), and five patients (2.7\%) suffered from a polycystic kidney disease with tuberous sclerosis (PKDTS), which is a contiguous gene deletion syndrome. Most children lived with both parents at home $(n=151,82.1 \%)$. Forty percent $(n=74)$ of patients attended a school with a special focus on learning, and mental and physical development, whereas the majority of small children attended kindergarten $(n=49,26.6 \%)$. Among the respondents, mothers had a mean age of 41 years, and fathers were older, on average, with a mean age of 43 years. The occupational situations of parents revealed that $70 \%$ of mothers $(n=128)$ and $91 \%$ of fathers $(n=167)$ were employed. Additional sociodemographic and clinical characteristics and affected family members are presented in Table 1. The majority of patients were affected by a range of TSC organ manifestations, including 169 (91.8\%) patients diagnosed with epilepsy, 158 (85.9\%) showing skin manifestations, $153(83.2 \%)$ presenting with various structural brain disorders, and 123 (66.8\%) reporting heart and circulatory system disorders. Additional details can be found in Table 2. 


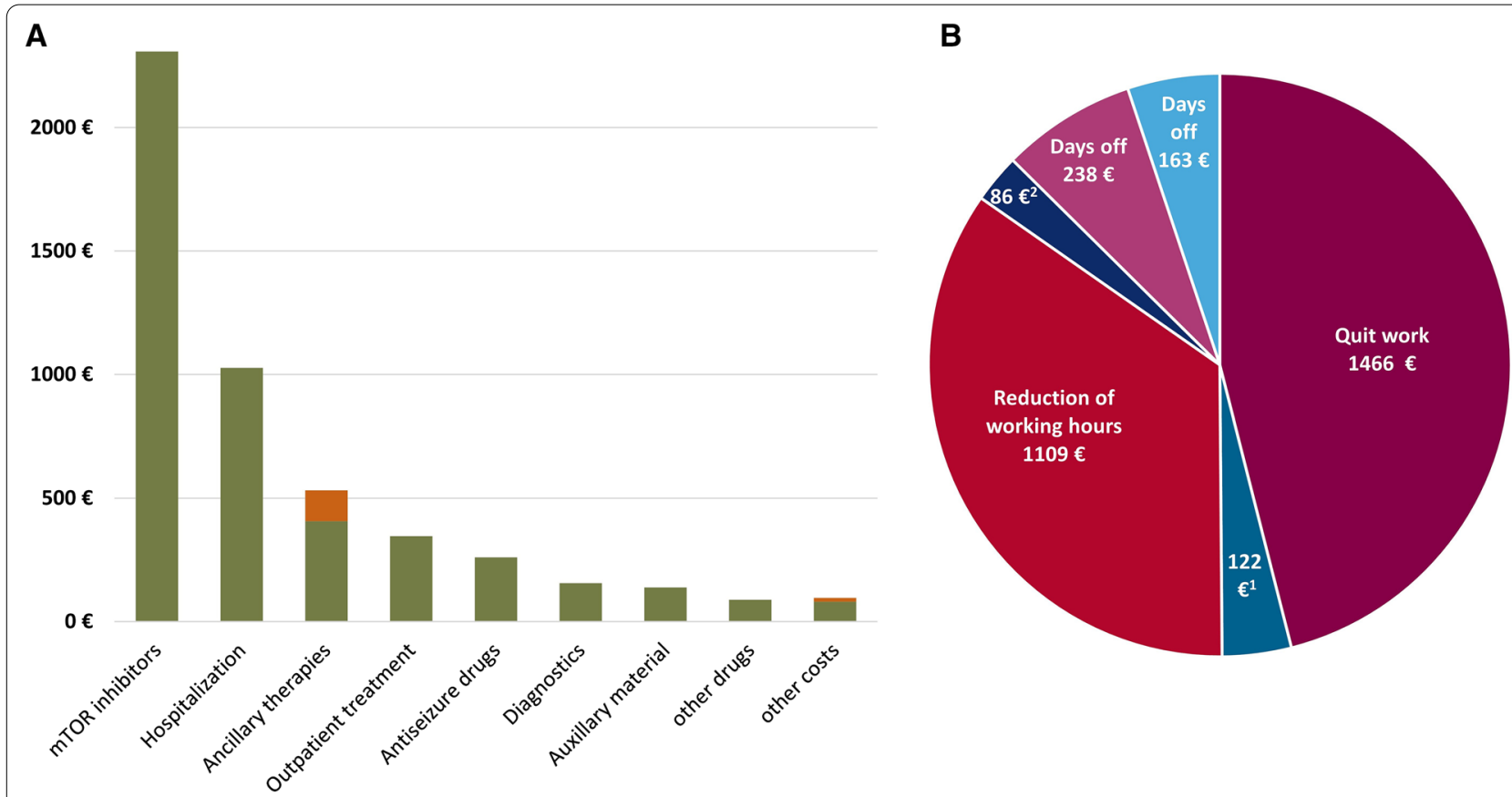

Fig. 1 Breakdown of total direct costs (A), with co-payments in orange, per patient over 3 months and total indirect costs for caregivers over 3 months (B). Maternal costs are in red and paternal costs are in blue. ${ }^{1}$ quit work; ${ }^{2}$ reduction of working hours

\section{Direct costs}

The mean total direct costs were calculated at EUR 4949 (95\% CI: EUR 4088-5863, median: EUR 2062) per study participant for the reported 3-month study period, and details are presented in Table 3 and Fig. 1A. Direct medical costs were primarily associated with the costs of drug treatment $(53.7 \%$ of total direct costs, mean: EUR 2658 per 3 months, 95\% CI: EUR 2060-3297, median: EUR 321 ) and hospitalization (20.8\% of total direct costs, mean: EUR 1027, 95\% CI EUR 579-1503; median EUR 0).

Costs for mTOR inhibitors (everolimus, $n=46$ and sirolimus, $n=3$ ) were the primary direct cost components with a mean of EUR 2309 (46.6\% of total direct costs, 95\% CI: EUR 1715-2928, median: EUR 0), which was greater than the costs associated with ASDs (synonymous to anticonvulsants or antiepileptic drugs) which were associated with a mean cost of EUR 260 (5.3\% of total direct costs, 95\% CI: EUR 213-312, median: EUR 159). The patients used a mean number of 1.8 ASDs (SD 0.8 , median 2 , range $0-4)$. The five most frequently prescribed ASDs included oxcarbazepine $(n=49 ; 26.6 \%)$, vigabatrin $(n=48,26.1 \%)$, lamotrigine $(n=47 ; 25.5 \%)$, valproate $(n=46 ; 25 \%)$, and levetiracetam $(n=25 ; 13.6 \%)$. ASD monotherapy was prescribed to $32.6 \%(n=60)$ of all participants and was associated with lower costs than ASD polytherapy, comprising two or more ASDs (each $p<0.001)$. The detailed costs and daily dosages of the various ASDs are listed in Table 4.
In total, 41 (22.3\%) of the included children and adolescents were admitted at least once to a hospital because of TSC during the 3-month study period. Overall, 49 admissions were reported, with a mean length of stay of 6.04 days (SD 7.5 days; median 3 days, range 1-42 days). Seizures were the reported reason for 23 admissions, whereas 22 admissions were due to diagnostics, and four additional admissions were associated with other TSCrelated causes.

Ancillary treatments, such as occupational therapy, physiotherapy, and speech therapy were prescribed to 116 participants (63\%), and with costs as high as EUR 407 per 3 months, representing $8.2 \%$ of total direct costs $(95 \%$ CI: EUR 345-472, median: EUR 212). In addition, EUR 125 in the 3 -month study period were directly paid by the families for therapies.

\section{Care needs and nursing care-level costs}

Sixty-five percent $(n=120)$ of patients were categorized as meeting the care levels defined by the "Pflegebedürftigkeits scale" (2.7\% Level I ['low impairment of independence']; $12 \%$ Level II ['significant need for care']; $20.7 \%$ Level III ['heavy need for care']; 18.5\% Level IV ['most difficult to care for']; and $11.4 \%$ Level V ['most difficult to care for and special demands of nursing care']). Approximately $3 \%(n=5)$ of patients did not meet the Level $\mathrm{I}-\mathrm{V}$ criteria but were reported as being in need of care 
according to their caregivers. Only $32 \%$ of patients were reported as not in need of care. The costs for nursing care were calculated as EUR 1163 (95\% CI: EUR 1027-1314, median: EUR 1635) per 3-month period and EUR 4652 annually, assuming that care is provided by family members. Parents reported that they incurred further costs for informal care, with a mean of EUR 20.8, and supervision, with a mean of EUR 27.6 per 3 -month period. In total, 123 patients $(66.8 \%)$ had a severely disabled pass between $70 \%$ and $100 \%$ (maximum $=100 \%$ ). No disability or disability $\leq 60 \%$ were identified in $33 \%(n=61)$ of patients.

\section{Indirect (productivity) costs}

All parents were of working age, and lost work time was recorded separately for mothers and fathers. In total, 111 parents reported that they had changed their working situation or remained out of work due to TSC in their child. Total indirect costs were calculated at a mean of EUR 3184 (95\% CI: EUR 2533-3811, median: EUR 645) over three months, or EUR 12,736 annually. Twenty-four mothers $(13.0 \%$, compared with $1.1 \%$ of fathers) reported that they quit working, 49 mothers reduced their working hours (26.6\%, compared with $3.8 \%$ of fathers), and 41 mothers missed days of work during the last three months due to TSC $(22.3 \%$, the same number of 41 [22.3\%] who missed days of work applied to fathers). Mean productivity costs over three months were estimated at EUR 1466, associated with mothers quitting work (EUR 122 for fathers); EUR 1109, associated with mothers' reduced working hours (EUR 86 for fathers); and EUR 238 associated with mothers' lost workdays (EUR 163 for fathers). The total mean maternal indirect costs totaled EUR 2813 (95\% CI: EUR 2221-3394, median: EUR 215,) over three months, or EUR 11,252 annually, whereas the total indirect costs for fathers were calculated at EUR 372 (95\% CI: EUR 193-586, median: EUR 0) over three months, or EUR 1488 annually. These details are provided in Table 5 and Fig. $1 \mathrm{~B}$.

Twenty-five (13.6\%) of the adolescents included in this study were older than 16 years of age. Five of them were working, two were unable to work or attend school due to TSC, and 18 were in school, at university, or in vocational training. The mean indirect costs were calculated at EUR 1002 (95\% CI: EUR 103-2005, median: EUR 0) per 3 months, which were due to 12 days off work due to TSC in one adolescent and the two individuals who were unable to work or attend school.

Cost drivers of direct, indirect, and nursing care-level costs To identify potential cost-driving factors, we performed univariate analyses of total direct, total indirect, and nursing care-level costs, and a number of demographic and clinical patient characteristics. The indirect costs
Table 1 Sociodemographic and clinical characteristics $(n=184)$

\begin{tabular}{|c|c|}
\hline & All patients $n=184$ \\
\hline \multirow[t]{3}{*}{ Age in years ${ }^{1}$} & $9.8 \pm 5.3$ \\
\hline & range \\
\hline & $0.7-21.8$ \\
\hline Sex & $\%(n)$ \\
\hline Male & $51.6(95)$ \\
\hline Female & $48.4(89)$ \\
\hline \multirow[t]{3}{*}{ Age at first symptoms due to TSC $^{1}$} & $0.8 \pm 1.3$ \\
\hline & range \\
\hline & $0-7.7$ \\
\hline \multirow[t]{3}{*}{ Age at TSC diagnosis in years ${ }^{1}$} & $1.3 \pm 2.1$ \\
\hline & range \\
\hline & $0-12.1$ \\
\hline TSC diagnosis before birth by ultrasound & $\%(n)$ \\
\hline No & $81.5(150)$ \\
\hline Yes & $18.5(34)$ \\
\hline Genetics & $\%(n)$ \\
\hline TSC1-gene & $13.6(25)$ \\
\hline TSC2-gene & $46.2(85)$ \\
\hline TSC2/PKD1 contiguous-gene & $2.7(5)$ \\
\hline No genetic test & $15.2(28)$ \\
\hline No genetic mutation & $4.9(9)$ \\
\hline Unknown & $17.3(32)$ \\
\hline Affected family members by TSC & $\%(n)$ \\
\hline No & $85.3(157)$ \\
\hline Yes & $14.7(27)$ \\
\hline Mother affected $(23.9 \text { years })^{2}$ & $7.6(14)$ \\
\hline Father affected (33.6 years) $)^{2}$ & $6.5(12)$ \\
\hline Sibling affected $(8.8 \text { years })^{2}$ & $4.9(9)$ \\
\hline Grandparents affected & $2.2(4)$ \\
\hline \multicolumn{2}{|l|}{ Parents'age in years ${ }^{1}$} \\
\hline Mother & $40.8 \pm 7.0$ \\
\hline Father & $43.4 \pm 7.4$ \\
\hline Living conditions & $\%(n)$ \\
\hline With mother and father & $82.1(151)$ \\
\hline Only with mother & $13.0(24)$ \\
\hline Only with father & $0.5(1)$ \\
\hline Other & $4.4(8)$ \\
\hline Childcare and School & $\%(n)$ \\
\hline School for children with special needs ${ }^{3}$ & $40.2(74)$ \\
\hline Kindergarten & $26.6(49)$ \\
\hline Primary mainstream school & $10.9(20)$ \\
\hline Secondary mainstream school & $8.2(15)$ \\
\hline Only at home & $6.0(11)$ \\
\hline Day care & $0.5(1)$ \\
\hline Employed & $0.5(1)$ \\
\hline Unknown/other & $7.1(13)$ \\
\hline
\end{tabular}

\footnotetext{
${ }^{1}$ Mean \pm standard deviation

${ }^{2}$ Mean age at TSC diagnosis of affected family members

${ }^{3}$ Learning, mental and physical development
} 
Table 2 Organ manifestations in TSC patients ${ }^{1}(n=184)$

\begin{tabular}{|c|c|c|}
\hline & $\%$ & $\mathbf{n}$ \\
\hline Epilepsy & 91.8 & 169 \\
\hline Recurrent seizures & 47.8 & 88 \\
\hline Seizure free $>1$ year or no seizures & 52.2 & 96 \\
\hline Structural brain disorders & 83.2 & 153 \\
\hline $\mathrm{SEGA}^{2}$ & 33.2 & 61 \\
\hline Cortical tubers & 76.1 & 140 \\
\hline Hydrocephalus & 3.3 & 6 \\
\hline Psychiatric disorders & 51.1 & 94 \\
\hline Heart and circulatory system & 66.8 & 123 \\
\hline Rhabdomyomas & 61.4 & 113 \\
\hline Hypertension & 6.0 & 11 \\
\hline Aneurysm Aorta & 1.1 & 2 \\
\hline Arrhythmia & 7.6 & 14 \\
\hline Kidney and urinary tract & 53.3 & 98 \\
\hline Chronic kidney dysfunction & 1.6 & 3 \\
\hline Angiomyolipomas & 45.7 & 84 \\
\hline Cysts & 29.9 & 55 \\
\hline Skin manifestations & 85.9 & 158 \\
\hline Hypomelanotic macules & 74.5 & 137 \\
\hline Angiofibromas & 60.3 & 111 \\
\hline Shagreen patches & 39.1 & 72 \\
\hline Forehead plaque & 3.3 & 6 \\
\hline Ungal/periungal fibromas & 1.1 & 2 \\
\hline Other disorders & 29.9 & 55 \\
\hline Iris or retinal hamartomas/astrocytomas & 19.0 & 35 \\
\hline Angiomyolipomas in other organ systems ${ }^{3}$ & 3.3 & 6 \\
\hline Cysts in other organ systems ${ }^{3}$ & 2.7 & 5 \\
\hline
\end{tabular}

${ }^{1}$ Respiratory system manifestations were not reported

${ }^{2}$ Subependymal giant cell astrocytoma

${ }^{3}$ Hormone system, Thyroid, Gastrointestinal, Liver, Spleen, Pancreas

of mothers and fathers were considered together. Polytherapy with two or more ASDs, the use of mTOR inhibitors, TSC manifestations, such as epilepsy, structural brain disorders, psychiatric and cardiac disease, and disability, were all associated with increased total costs according to the univariate analyses, which are detailed in Table 6. Younger age, polytherapy with two or more ASDs, TSC manifestations, such as epilepsy, psychiatric disease, and disability, were associated with higher indirect costs, and older age, polytherapy with two or more ASDs, TSC manifestations such, as epilepsy, psychiatric and kidney disease, and disability, were associated with increased nursing care-level costs according to the univariate analyses.

Overall, total direct, total indirect, and nursing costs increased as the number of affected organ systems increased (Table 6).
Multiple regression analyses revealed that polytherapy with two or more ASDs and the use of mTOR inhibitors were independent cost-driving factors for total direct costs. After applying a Bonferroni correction for eight comparisons, the significance threshold for the p-value was set to 0.00625 , and the variables were able to explain $53 \%\left(\mathrm{R}^{2}\right)$ of the total variance. Younger age and psychiatric disease were independent cost-driving factors for total indirect costs (corrected $p<0.00625 ; \mathrm{R}^{2}=19 \%$ ). Psychiatric disease and disability were independent cost-driving factors for nursing care-level costs (corrected $p<0.007$; $\left.\mathrm{R}^{2}=57 \%\right)$.

\section{Discussion}

This detailed, multicenter, COI study is based on a large sample of 184 patients and their caregivers within a single, national healthcare system and contributes important new information regarding the costs and costdriving factors associated with TSC in Europe. To enable comparisons with other COI studies, we aimed to capture the most comprehensive set of cost items related to epilepsy and other TSC organ manifestations [3, 34].

Previous studies have reported direct cost estimates for patients with TSC in Europe [11, 13, 35, 36] and North America [32, 33, 37-40]; however, no previous studies have provided indirect cost estimates for caregivers whose working lives are affected by TSC in their children [3]. The wider societal impacts determined for the indirect costs incurred by caregivers of patients with TSC were substantial, calculated at an annual mean of EUR 12,700, which exceeds the indirect costs of EUR 5250 reported for the parents of a general German population of children with epilepsy [21] but compares well with the EUR 19,150 calculated in Germany for the caregivers of children and adolescents with Dravet syndrome, a severe early-onset epileptic encephalopathy [41]. The results of the current study were comparable with the outcomes reported by other German studies examining refractory epilepsy [21, 41], which may be due to the use of the same methodology. The high indirect costs suggest that persisting seizures refractory to ASD polytherapy, psychiatric disease, and disability reflect a cost driver among patients with epileptic encephalopathies [42-44]. In line with these findings, we were able to show that TSC manifestations, such as epilepsy, psychiatric disease, and disability, were associated with increased indirect costs, indicating a high strain on the working lives of caregivers. We calculated the indirect costs for adolescents to be EUR 1002 per three months; however, this finding should be viewed with caution due to the limited number of adolescents of working age in our study population.

Another particular contribution of this study was the collection of data regarding the nursing requirements 
Table 3 Direct costs for a 3-month period for the total patient group ( $n=184$; in 2019 Euro)

\begin{tabular}{|c|c|c|c|c|c|c|c|c|}
\hline Cost components & Mean costs & $\mathrm{SD}^{1}$ & Minimum & Median & Maximum & $95 \% \mathrm{Cl}$ & $\begin{array}{l}\% \text { of total } \\
\text { direct costs }\end{array}$ & $\begin{array}{l}\text { Estimated } \\
\text { annual direct } \\
\text { costs }^{2}\end{array}$ \\
\hline Total direct costs & 4949 & 6079 & 0 & 2062 & 29,231 & $4088 ; 5863$ & 100 & 19,796 \\
\hline Medication $(n=168)$ & 2658 & 4557 & 0 & 321 & 21,546 & $2060 ; 3297$ & 53.7 & 10,632 \\
\hline mTOR inhibitors $*(n=49)$ & 2309 & 4435 & 0 & 0 & 20,054 & $1715 ; 2928$ & 46.6 & 9236 \\
\hline Antiseizure drugs $(n=154)$ & 260 & 378 & 0 & 159 & 3027 & $213 ; 312$ & 5.3 & 1040 \\
\hline Other prescription drugs $(n=62)$ & 72 & 352 & 0 & 0 & 3569 & $33 ; 122$ & 1.5 & 288 \\
\hline OTC drugs and supplements $(n=30)$ & 11 & 44 & 0 & 0 & 349 & $6 ; 17$ & 0.2 & 44 \\
\hline Emergency medication $(n=23)$ & 5 & 24 & 0 & 0 & 266 & $2 ; 9$ & 0.1 & 20 \\
\hline Hospitalization $(n=41)$ & 1027 & 3467 & 0 & 0 & 26,802 & $579 ; 1503$ & 20.8 & 4108 \\
\hline Ancillary therapies $(n=116)$ & 407 & 470 & 0 & 212 & 1951 & $345 ; 472$ & 8.2 & 1628 \\
\hline Outpatient treatment $(n=169)$ & 346 & 357 & 0 & 255 & 2250 & $298 ; 396$ & 7.0 & 1384 \\
\hline Diagnostics $(n=153)$ & 156 & 194 & 0 & 101 & 1370 & $130 ; 186$ & 3.2 & 624 \\
\hline Auxillary material $(n=19)$ & 138 & 738 & 0 & 0 & 8130 & $52 ; 241$ & 2.8 & 552 \\
\hline Rehabilitation $(n=2)$ & 27 & 287 & 0 & 0 & 3671 & $0 ; 67$ & 0.6 & 108 \\
\hline Emergency service use $(n=5)$ & 23 & 145 & 0 & 0 & 1200 & $7 ; 46$ & 0.5 & 92 \\
\hline Specific diets $(n=11)$ & 22 & 122 & 0 & 0 & 1100 & $8 ; 41$ & 0.4 & 88 \\
\hline Transport costs $(n=51)$ & 9 & 34 & 0 & 0 & 374 & $5 ; 14$ & 0.2 & 36 \\
\hline Co-payments for therapies $(n=64)$ & 125 & 297 & 0 & 0 & 2020 & $87 ; 167$ & 2.5 & 500 \\
\hline Other co-payments $(n=22)$ & 15 & 54 & 0 & 0 & 400 & $8 ; 23$ & 0.3 & 60 \\
\hline
\end{tabular}

${ }^{1}$ Standard deviation

${ }^{2}$ Estimation based on the mean costs in three months multiplied by four

$95 \% \mathrm{Cl}=95 \%$ Confidence interval using the bootstrap bias corrected and accelerated method

${ }^{*}$ Everolimus $n=46$, Sirolimus $n=3$, OTC $=$ over-the-counter

of the study population, as measured by the care grade allowances, which were among the most important cost components assessed, associated with annual expenditures totaling EUR 4650. This finding reinforced the significant effects of different organ manifestations, together with seizure-related costs, which were also reported by Skalicky et al. [40].

Generally, the results of this study indicated that the management of TSC results in considerable resource use, exceeding the costs of German epilepsy patients, in general. Epilepsy was the major TSC organ manifestation, reported in $91.8 \%$ of our cohort. Total annual direct healthcare costs were estimated at EUR 19,800 in this study, excluding care grade allowances. The direct costs related to TSC were primarily the result of mTOR inhibitor use (46.6\% of total direct costs, EUR 2309 per three months) and hospitalization (20.8\% of total direct costs, EUR 1027 per three months) and were impacted far less by ASD use (5.3\%, EUR 260) [45]. mTOR inhibitors were used by 49 children and adolescents $(26.6 \%$ of the cohort); therefore, our study provides unique COI data, reflecting the introduction and wide use of this drug class. The cost of mTOR inhibitor use is likely to decrease in the future as generic formulations become available, a phenomenon that has been well-demonstrated for other ASDs $[25,46]$. Although our study appears to agree with other COI studies regarding the contributions of hospitalization and ASD use [11, 13, 32, 33, 35, 36, 39, 40, 47, 48] (for details, please refer to Table 7) performing direct comparisons against studies from different settings and different countries proved to be difficult, as the observed variations were likely associated with a variety of contributing factors including differences in definition, policy, measurements, and population (such as the combination of TSC/epilepsy cohorts). Furthermore, the resource use might change over time according to changes in organ manifestation during the lifetime of TSC patients [3, 49]. Overall, the medical and care-related expenditures among patients with TSC are high and appear to be driven by the severity of each of the multiple disease manifestations (Additioanl file 1). Preventive treatment with new and thus expensive disease-modifying drugs may be outweighed by reductions in the substantial direct and indirect costs, however disease-modifying treatment would have to start in early childhood [10, 50, 51]. 
Table 4 Prescription patterns and costs of anti-seizure drugs (ASDs) for a 3-month period (in 2019 Euro)

\begin{tabular}{|c|c|c|c|c|c|c|c|c|}
\hline Medication costs & $n$ & $\begin{array}{l}\text { Mean costs per } \\
3 \text { months }\end{array}$ & $\mathrm{SD}^{1}$ & Minimum & Median & Maximum & $95 \% \mathrm{Cl}$ & $p$ value $^{2}$ \\
\hline All patients & 184 & $€ 260$ & 378 & $€ 0$ & $€ 159$ & $€ 3027$ & $€ 213 ; 312$ & \\
\hline No ASDs (16.3\%) & 30 & 0 & & & & & & \\
\hline Monotherapy (32.6\%) & 60 & $€ 158$ & 211 & $€ 7$ & $€ 102$ & $€ 1369$ & $€ 117 ; 208$ & $<0.001^{3}$ \\
\hline 2 ASDs (37.0\%) & 68 & $€ 283$ & 191 & $€ 27$ & $€ 241$ & $€ 810$ & $€ 242 ; 328$ & $<0.001^{4}$ \\
\hline$\geq 3$ ASDs (14.1\%) & 26 & $€ 736$ & 708 & $€ 167$ & $€ 519$ & $€ 3027$ & $€ 503 ; 994$ & $<0.004^{5}$ \\
\hline Prescribed medication & $n$ & Mean daily dose & $\mathrm{SD}^{1}$ & Minimum & Median & Maximum & $\begin{array}{l}\text { Mean costs per } \\
3 \text { months }\end{array}$ & $\mathrm{SD}^{1}$ \\
\hline Oxcarbazepine (26.6\%) & 49 & $1006 \mathrm{mg}$ & $532 \mathrm{mg}$ & $150 \mathrm{mg}$ & $900 \mathrm{mg}$ & $2700 \mathrm{mg}$ & $€ 140$ & 74 \\
\hline Vigabatrine (26.1\%) & 48 & $1480 \mathrm{mg}$ & $754 \mathrm{mg}$ & $500 \mathrm{mg}$ & $1250 \mathrm{mg}$ & $3500 \mathrm{mg}$ & $€ 267$ & 136 \\
\hline Lamotrigine (25.5\%) & 47 & $213 \mathrm{mg}$ & $163 \mathrm{mg}$ & $6 \mathrm{mg}$ & $200 \mathrm{mg}$ & $700 \mathrm{mg}$ & $€ 53$ & 41 \\
\hline Valproate (25.0\%) & 46 & $850 \mathrm{mg}$ & $373 \mathrm{mg}$ & $150 \mathrm{mg}$ & $840 \mathrm{mg}$ & $1650 \mathrm{mg}$ & $€ 39$ & 17 \\
\hline Levetiracetam (13.6\%) & 25 & $1574 \mathrm{mg}$ & $1287 \mathrm{mg}$ & $500 \mathrm{mg}$ & $900 \mathrm{mg}$ & $5250 \mathrm{mg}$ & $€ 105$ & 86 \\
\hline Lacosamide (6.5\%) & 12 & $284 \mathrm{mg}$ & $91 \mathrm{mg}$ & $120 \mathrm{mg}$ & $275 \mathrm{mg}$ & $400 \mathrm{mg}$ & $€ 619$ & 198 \\
\hline Clobazame (4.9\%) & 9 & $29 \mathrm{mg}$ & $50 \mathrm{mg}$ & $3 \mathrm{mg}$ & $13 \mathrm{mg}$ & $150 \mathrm{mg}$ & $€ 78$ & 136 \\
\hline Topiramate (3.3\%) & 6 & $194 \mathrm{mg}$ & $132 \mathrm{mg}$ & $38 \mathrm{mg}$ & $150 \mathrm{mg}$ & $400 \mathrm{mg}$ & $€ 128$ & 87 \\
\hline Brivaracetam (2.7\%) & 5 & $195 \mathrm{mg}$ & $67 \mathrm{mg}$ & $125 \mathrm{mg}$ & $200 \mathrm{mg}$ & $300 \mathrm{mg}$ & $€ 450$ & 155 \\
\hline Ethosuximide (2.7\%) & 5 & $440 \mathrm{mg}$ & $134 \mathrm{mg}$ & $300 \mathrm{mg}$ & $500 \mathrm{mg}$ & $600 \mathrm{mg}$ & $€ 79$ & 24 \\
\hline Sulthiame (2.2\%) & 4 & $106 \mathrm{mg}$ & $69 \mathrm{mg}$ & $25 \mathrm{mg}$ & $113 \mathrm{mg}$ & $175 \mathrm{mg}$ & $€ 64$ & 42 \\
\hline Carbamazepine (2.2\%) & 4 & $963 \mathrm{mg}$ & $256 \mathrm{mg}$ & $600 \mathrm{mg}$ & $1025 \mathrm{mg}$ & $1200 \mathrm{mg}$ & $€ 47$ & 13 \\
\hline Phenytoin (1.6\%) & 3 & $250 \mathrm{mg}$ & $87 \mathrm{mg}$ & $200 \mathrm{mg}$ & $200 \mathrm{mg}$ & $350 \mathrm{mg}$ & $€ 20$ & 7 \\
\hline Rufinamid (1.6\%) & 3 & $1333 \mathrm{mg}$ & $945 \mathrm{mg}$ & $600 \mathrm{mg}$ & $1000 \mathrm{mg}$ & $2400 \mathrm{mg}$ & $€ 799$ & 566 \\
\hline Zonisamide (1.6\%) & 3 & $147 \mathrm{mg}$ & $50 \mathrm{mg}$ & $100 \mathrm{mg}$ & $140 \mathrm{mg}$ & $200 \mathrm{mg}$ & $€ 243$ & 83 \\
\hline Other ASDs* (4.9\%) & 9 & & & & & & & \\
\hline
\end{tabular}

${ }^{1}$ Standard deviation, $95 \% \mathrm{Cl}=95 \%$ Confidence interval using the bootstrap bias corrected and accelerated method

${ }^{2}$ Mann-Whitney-U-test; ${ }^{3}$ Monotherapy vs. $\geq 3$ ASDs, ${ }^{4}$ Monotherapy vs. 2 ASDs, 2 ASDs vs $\geq 3$ ASDs

${ }^{*}$ (Cannabidiol $n=2$, Eslicarbazepine acetate $n=1$, Felbamate $n=1$, Perampanel $n=2$, Phenobarbital $n=2$, Potassium bromide $n=1$ )

Table 5 Indirect costs to caregivers for a 3-month period (in 2019 Euro)

\begin{tabular}{|c|c|c|c|c|c|c|c|c|}
\hline Indirect costs components & $\mathrm{n}^{1}$ & Mean costs & $S^{2}$ & Minimum & Median & Maximum & $95 \% \mathrm{Cl}$ & $\begin{array}{l}\text { Estimated } \\
\text { annual } \\
\text { costs }^{3}\end{array}$ \\
\hline Maternal indirect costs & 96 & 2813 & 3950 & 0 & 215 & 11,241 & $2221 ; 3394$ & 11,252 \\
\hline Quit work & 24 & 1466 & 3796 & 0 & 0 & 11,241 & $916 ; 2016$ & 5864 \\
\hline Reduction of working hours & 49 & 1109 & 2136 & 0 & 0 & 8774 & $808 ; 1438$ & 4436 \\
\hline Days off due to TSC & 41 & 238 & 628 & 0 & 0 & 4300 & $153 ; 332$ & 952 \\
\hline Paternal indirect costs & 48 & 372 & 1345 & 0 & 0 & 11,241 & $193 ; 586$ & 1488 \\
\hline Quit work & 2 & 122 & 1169 & 0 & 0 & 11,241 & $0 ; 306$ & 488 \\
\hline Reduction of working hours & 7 & 86 & 531 & 0 & 0 & 5621 & $22 ; 169$ & 344 \\
\hline Days off due to TSC & 41 & 163 & 452 & 0 & 0 & 3440 & $101 ; 233$ & 652 \\
\hline Total parents & 111 & 3184 & 4326 & 0 & 645 & 22,482 & $2533 ; 3811$ & 12,736 \\
\hline
\end{tabular}

$95 \% \mathrm{Cl}=95 \%$ Confidence interval using the bootstrap bias corrected and accelerated method

${ }^{1}$ Parents of working age

${ }^{2}$ Standard deviation

${ }^{3}$ Estimation based on the mean costs in three months multiplied by four 


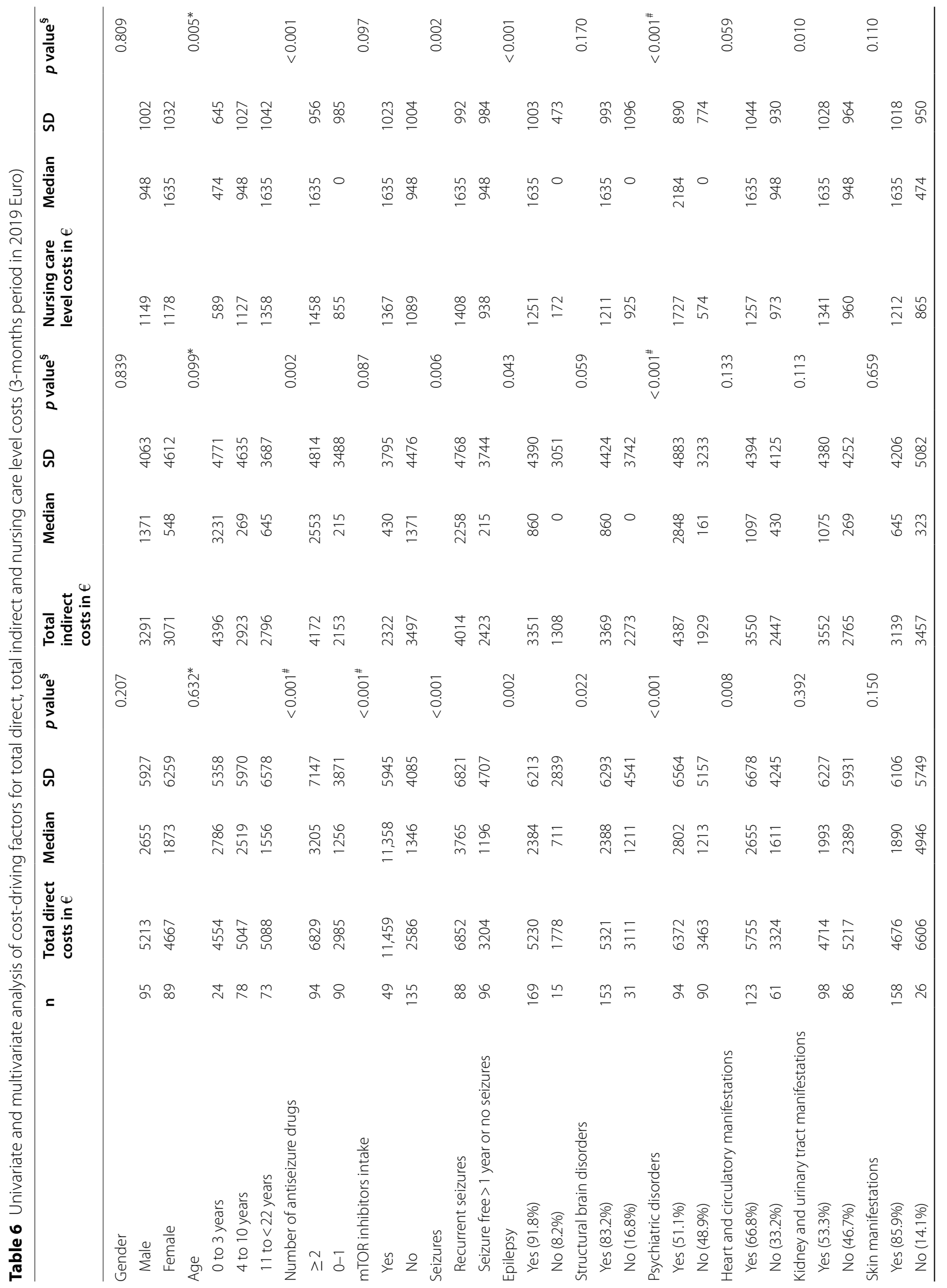




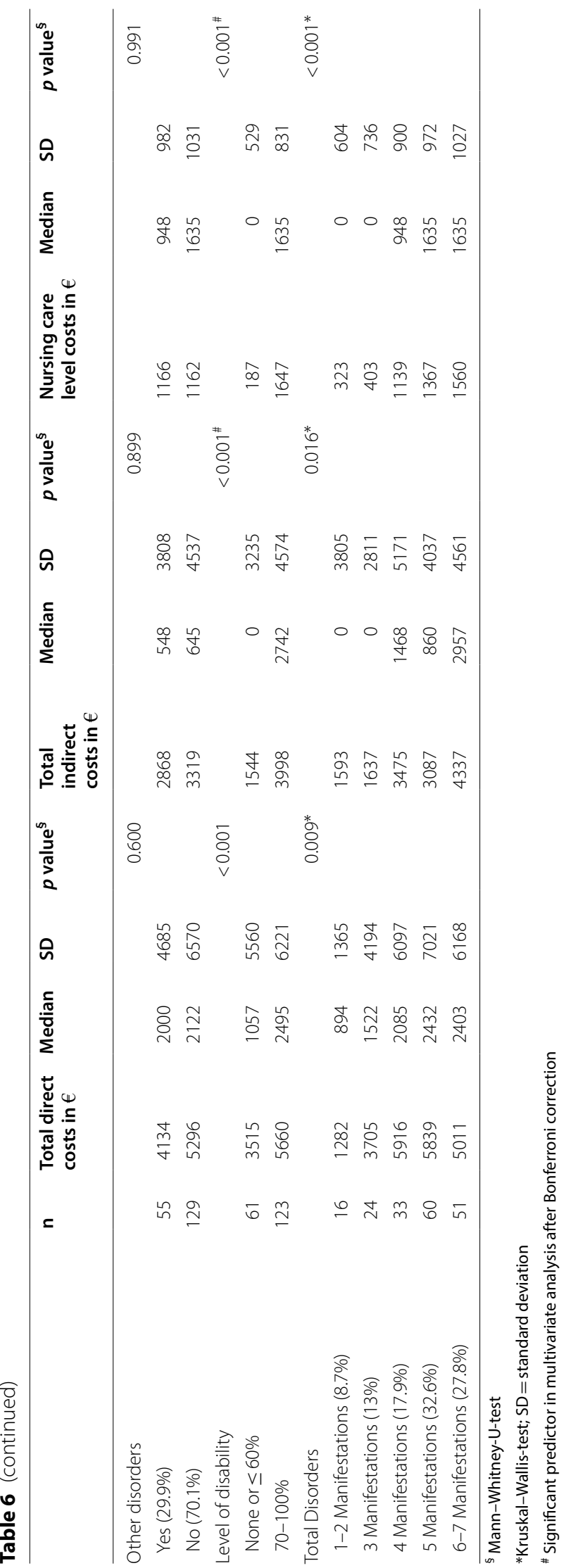




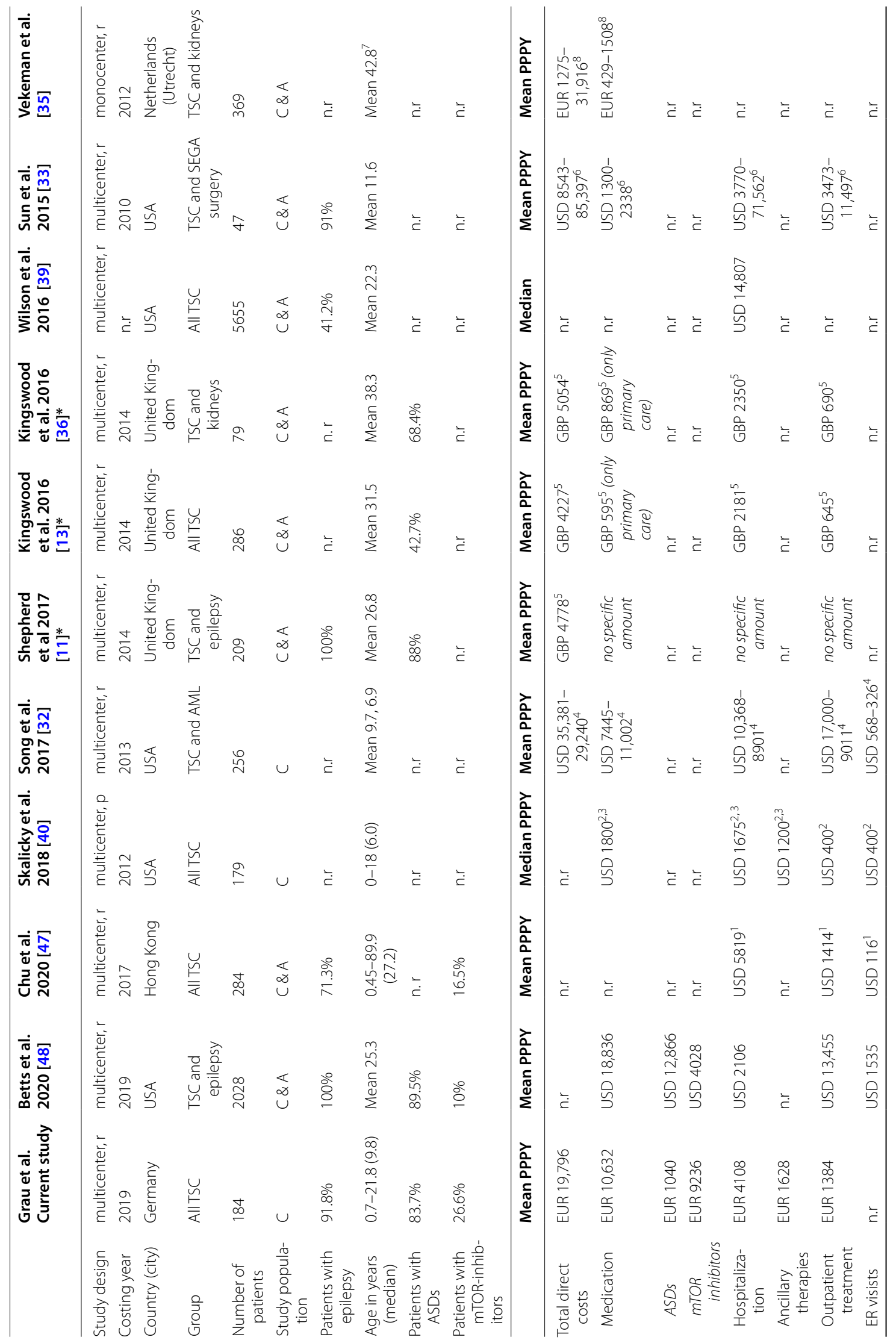


Gran et al. Orphanet J Rare Dis <wide> <wide> (2021) 16:282

Page 13 of 16

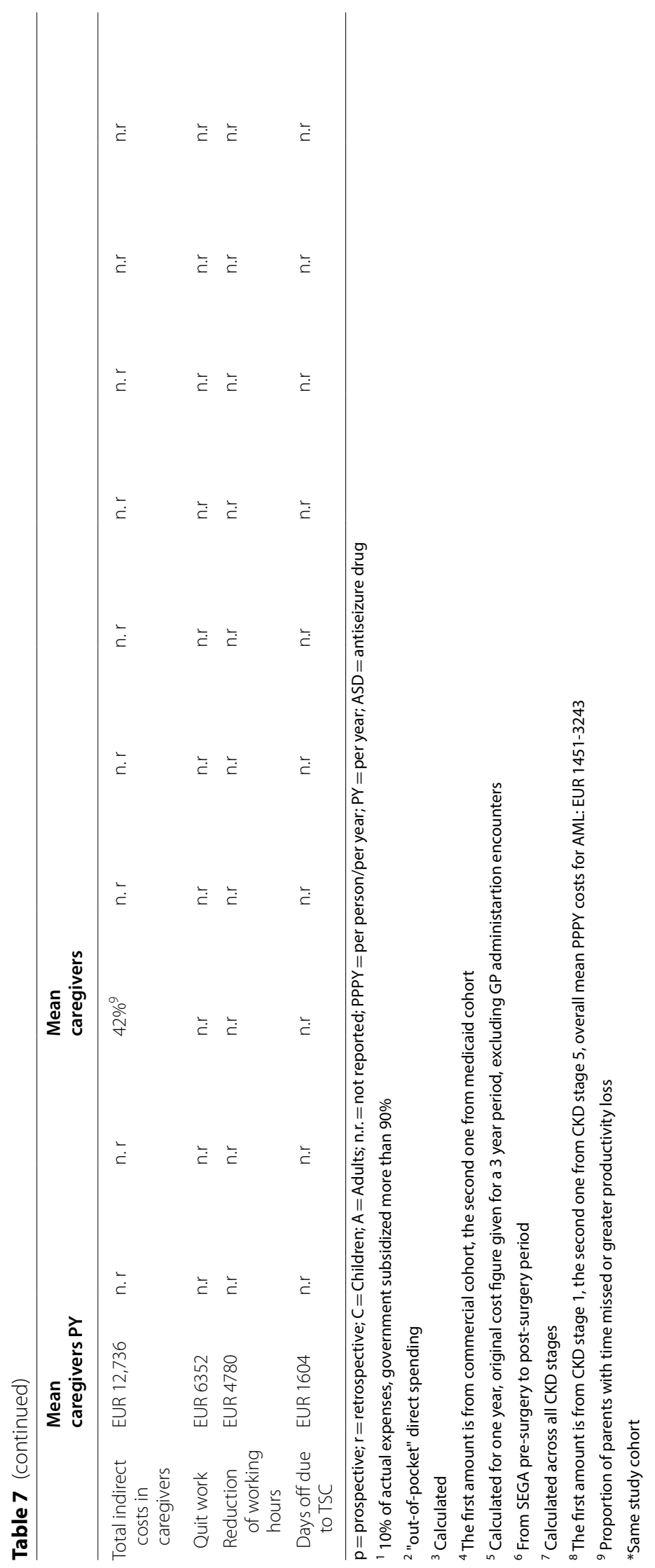




\section{Limitations}

Potential limitations associated with the questionnaire used in this study include recall bias regarding the three-month-old events, which might result in incomplete and underestimated costs. However, a validation of three-months recall for all items and of twelve-months recall regarding high-impact events like hospitalization or emergency calls with a prospective diary covering three months showed an excellent overlap in patients with Dravet syndrome, another developmental and epileptic encephalopathy [41]. Furthermore, although the sample consisted of patients recruited from multiple clinics and centers across Germany and through the patient advocacy group, whether the sample is representative of TSC patients in Germany remains challenging to determine due to the difficulty of estimating patient numbers for rare diseases. As the patients were approached by different physicians such as neuropediatricians, neurologists and nephrologists as well as through the patient advocacy group, we cannot reliably calculate a response rate as some patients were contacted several times. The use of costly treatments, such as everolimus, might be overestimated because several university centers participated in this study. In addition, the interpretation of the cost driver analysis must consider the limited sample size; however, the significance of multiple organ manifestations in the current study aligns well with earlier studies, which reported that the number of organ manifestations was a significant cost driver [11]. In addition, skewness was observed in the cost calculations, indicated by the disparities observed for some mean and median costs. We did not conduct any sensitivity analyses to test for uncertainty or any alternative costs. The major strength of the present study was the sample size of 184 patients and caregivers, which can be considered a large sample, given the relative rarity of TSC, as well the inclusion of the relatively new class of mTOR inhibitors in the cost analysis for the treatment of children and adolescents with TSC.

\section{Conclusions}

Medical and care-related expenditures among patients with TSC are high and appear to be driven by the severity of disease manifestations. In the long term, high direct costs might be outweighed by the preventive potential and multi-organ benefits of newer therapies. Productivity losses represent a major source of costs and may be addressed by improving socio-medical support systems and therapeutic interventions. Efforts should be focused on reducing work absenteeism and the rate at which caregivers stop working entirely while maintaining the quality of care provided to children and adolescents with TSC.

\section{Supplementary Information}

The online version contains supplementary material available at https://doi. org/10.1186/s13023-021-01899-x.

Additional file 1. Supplementary Table 1. Direct costs related to TSC manifestations.

\section{Acknowledgements}

The authors would like to thank all of the patients and caregivers who contributed to this survey and the German patient advocacy group Tuberöse Sklerose Deutschland e.V., for their help with the recruitment of participants. This study was supported by the State of Hessen through a LOEWE-Grant to the CePTER Consortium (https://www.uni-frankfurt.de/67689811).

\section{Authors' contributions}

JG, JPZ, SSB, GK, CH, AWK, MK, MS, FR and AS developed the idea for this study. $J G$ and AS conceived the paper, collected the data, and performed statistical analysis. JG and AS created the charts and figures. JG, JPZ and AS performed the review of cost-of-illness studies. All authors wrote the paper, discussed the results, contributed to the final manuscript, and approved the final manuscript for publication.

\section{Funding}

Open Access funding enabled and organized by Projekt DEAL. This study was supported by a LOEWE Grant from the State of Hessen for the "Center for Personalized Translational Epilepsy Research" (CePTER), Goethe-University Frankfurt, Frankfurt am Main, Germany.

\section{Availability of data and materials}

The datasets analysed during the current study are available from the corresponding author on reasonable request.

\section{Declarations}

\section{Ethics approval and consent to participate}

This study received ethics approval by the Goethe-University Frankfurt (reference 324/18) and all participants provided informed consent.

\section{Consent for publication}

Not applicable.

\section{Competing interests}

JPZ reports speakers' honoraria and travel grants from Eisai and Desitin Arzneimittel. SS-B reports personal fees from Eisai, Desitin Pharma, GW Pharmaceuticals companies, LivaNova, UCB, and Zogenix. GK reports personal fees from Desitin Arzneimittel, Eisai, GW Pharmaceuticals companies, UCB, Novartis, Takeda, and Zogenix. AW-K reports personal fees from Desitin Arzneimittel, GW Pharmaceuticals companies, Nutricia GmbH, Vitaflo, and UCB. TB reports personal fees from Eisai, Desitin Arzneimittel, GW Pharma, Novartis, Nutricia, Shire, Takeda, UCB Pharma and Zogenix. AB reports personal fees from Desitin Arzneimittel $\mathrm{GmbH}$, Eisai GmbH, Shire GmbH, UCB Pharma GmbH, and ViroPharma $\mathrm{GmbH}$. BF reports personal fees from Desitin Arzneimittel, Novartis and UCB. JJ reports personal fees from Eisai, GW Pharmaceuticals companies, Zogenix and has been supported by the German Research Foundation (DFG; JA 1725/4-1). KMK reports personal fees from UCB Pharma, Novartis Pharma AG, Eisai, and GW Pharmaceuticals, grants from the federal state Hessen through the LOEWE program and from the Canadian Institutes of Health Research. KAK reports personal fees from GW Pharmaceuticals companies and Zogenix and was supported by the Berta-Ottenstein-Program for Clinician 
Scientists from the Faculty of Medicine, University of Freiburg. TM reports personal fees and grants from Arvelle Therapeutics, Eisai, GW Pharmaceuticals companies, UCB, and Zogenix. HM reports personal fees from Desitin Arzneimittel, UCB, Novartis and Zogenix. SM reports grants from Novartis, UCB, Shire, Deutsche Forschungsgemeinschaft and Epilepsiestiftung Dr. Wolf. KMS reports personal fees from Nutricia, Desitin Arzneimittel, Shire, Medice, Novartis and UCB. MS reports personal fees from Novartis. RT reports personal fees from Eisai, Desitin, PTC Therap., Roche, Sanofi Genzyme. BW reports fees and compensation for travel expenses from Eisai, Takeda/Shire, Ipsen and PharmAllergan. FR reports personal fees from Arvelle Therapeutics, Desitin Arzneimittel, Eisai, GW Pharmaceuticals companies, Novartis, Medtronic, and UCB, and grants from the Detlev-Wrobel-Fonds for Epilepsy Research, the Deutsche Forschungsgemeinschaft, the LOEWE Programme of the State of Hesse, and the European Union. AS reports personal fees and grants from Arvelle Therapeutics, Desitin Arzneimittel, Eisai, GW Pharmaceuticals companies, Marinus Pharma, UCB, and Zogenix. The other authors declare that they have no competing interests.

\section{Author details}

${ }^{1}$ Epilepsy Center Frankfurt Rhine-Main and Department of Neurology, GoetheUniversity Frankfurt, Schleusenweg 2-16 (Haus 95), 60528 Frankfurt am Main, Germany. ${ }^{2}$ Center for Personalized Translational Epilepsy Research (CePTER), Goethe-University Frankfurt, Frankfurt am Main, Germany. ${ }^{3}$ Department of Neuropediatrics, Goethe-University Frankfurt, Frankfurt am Main, Germany. ${ }^{4}$ St. Bonifatius Hospital, Lingen, Germany. ${ }^{5}$ Department of Neuropediatrics, Vivantes Klinikum Neukölln, Berlin, Germany. ${ }^{6}$ Epilepsy Center Kork, Clinic for Children and Adolescents, Kehl-Kork, Germany. ${ }^{7}$ Department of Neuropediatrics, University Hospital for Children and Adolescents, Rostock, Germany. ${ }^{8}$ Neuropediatric Practice, Hirschaid, Germany. ${ }^{9}$ Department of General Pediatrics, Division of Neuropediatrics, University Hospital Münster, Münster, Germany. ${ }^{10}$ Department of Neuropediatrics, Justus-Liebig-University Gießen, Gießen, Germany. ${ }^{11}$ Department of Neuropediatrics, Clinic for Pediatric Kidney, Liver and Metabolic Diseases, Hannover Medical School, Hannover, Germany. ${ }^{12}$ Department of Neuropediatrics, Leipzig University Hospital for Children and Adolescents, Leipzig, Germany. ${ }^{13}$ Epilepsy Center Hessen and Department of Neurology, Philipps-University Marburg, Marburg (Lahn), Germany. ${ }^{14}$ Department of Neuropediatrics and Muscle Disorders, Center for Pediatrics, Medical Center, Faculty of Medicine, University of Freiburg, Freiburg i.Br., Germany. ${ }^{15}$ Department of Pediatrics and Clinical Neurosciences, Cumming School of Medicine, University of Calgary, Calgary, AB, Canada. ${ }^{16}$ Departments of Clinical Neurosciences, Medical Genetics and Community Health Sciences, Hotchkiss Brain Institute \& Alberta Children's Hospital Research Institute, Cumming School of Medicine, University of Calgary, Calgary, AB, Canada. ${ }^{17}$ Berta-Ottenstein-Programme, Faculty of Medicine, University of Freiburg, Freiburg i.Br., Germany. ${ }^{18} \mathrm{Clinic}$ for Neuropediatrics and Neurorehabilitation, Epilepsy Center for Children and Adolescents, Schön Clinic Vogtareuth, Vogtareuth, Germany. ${ }^{19}$ Research Institute, Rehabilitation, Transition and Palliation, PMU Salzburg, Salzburg, Austria. ${ }^{20}$ Department of Pediatrics, Klinikum Worms, Worms, Germany. ${ }^{21}$ Department of Pediatrics, University Medicine Mainz, Mainz, Germany. ${ }^{22}$ Epilepsy Center Kleinwachau, Dresden-Radeberg, Germany. ${ }^{23}$ Department of Pediatric Neurology, Psychosomatics and Pain Management, Klinikum Stuttgart, Stuttgart, Germany. ${ }^{24}$ Department of Neuropediatrics, Children's Hospital at University Medical Center Homburg, Homburg, Germany. ${ }^{25}$ Department of Neuropediatrics, Christian-Albrechts-University Kiel \& University Hospital Schleswig-Holstein, Campus Kiel, Kiel, Germany. ${ }^{26} \mathrm{Epi}-$ lepsy Center for Children, Brandenburg Medical School, University Hospital Neuruppin, Neuruppin, Germany. ${ }^{27}$ Department of Neuropediatrics, University Hospital Tübingen, Tübingen, Germany. ${ }^{28}$ Klinikum Kempten, Klinikverbund Allgäu, Kempten (Allgäu), Germany. ${ }^{29}$ Department of Neuropediatrics, University of Witten/Herdecke, Herdecke, Germany. ${ }^{30}$ Division of Pediatric Epileptology, Centre for Paediatrics and Adolescent Medicine, University Hospital Heidelberg, Heidelberg, Germany. ${ }^{31}$ Department of Neuropediatrics and Socialpediatrics, University Hospital of Ruhr University Bochum, Bochum, Germany ${ }^{32}$ Department of Neuropediatrics, Friedrich-Alexander University of Erlangen-Nürnberg, Erlangen, Germany. ${ }^{33}$ Department of Neuropediatrics, Klinikum Kassel, Kassel, Germany.

Received: 21 November 2020 Accepted: 29 May 2021 Published online: 21 June 2021

\section{References}

1. Hong $\mathrm{CH}$, Darling TN, Lee $\mathrm{CH}$. Prevalence of tuberous sclerosis complex in Taiwan: a national population-based study. Neuroepidemiology. 2009;33(4):335-41.

2. Shepherd CW, Beard CM, Gomez MR, Kurland LT, Whisnant JP. Tuberous sclerosis complex in Olmsted County, Minnesota, 1950-1989. Arch Neurol. 1991;48(4):400-1.

3. Zöllner JP, Franz DN, Hertzberg C, Nabbout R, Rosenow F, Sauter M, Schubert-Bast S, Wiemer-Kruel A, Strzelczyk A. A systematic review on the burden of illness in individuals with tuberous sclerosis complex (TSC). Orphanet J Rare Dis. 2020;15(1):23.

4. O'Callaghan FJ, Shiell AW, Osborne JP, Martyn CN. Prevalence of tuberous sclerosis estimated by capture-recapture analysis. Lancet. 1998;351(9114):1490.

5. Hong $\mathrm{CH}$, Tu HP, Lin JR, Lee $\mathrm{CH}$. An estimation of the incidence of tuberous sclerosis complex in a nationwide retrospective cohort study (1997-2010). Br J Dermatol. 2016;174(6):1282-9.

6. Ebrahimi-Fakhari D, Mann LL, Poryo M, Graf N, von Kries R, Heinrich B, Ebrahimi-Fakhari D, Flotats-Bastardas M, Gortner L, Zemlin M, et al. Incidence of tuberous sclerosis and age at first diagnosis: new data and emerging trends from a national, prospective surveillance study. Orphanet J Rare Dis. 2018;13(1):117.

7. Curatolo P, Moavero R, de Vries PJ. Neurological and neuropsychiatric aspects of tuberous sclerosis complex. Lancet Neurol. 2015;14(7):733-45.

8. Sancak O, Nellist M, Goedbloed M, Elfferich P, Wouters C, Maat-Kievit A, Zonnenberg B, Verhoef S, Halley D, van den Ouweland A. Mutational analysis of the TSC1 and TSC2 genes in a diagnostic setting: genotypephenotype correlations and comparison of diagnostic DNA techniques in Tuberous Sclerosis Complex. Eur J Hum Genet. 2005;13(6):731-41.

9. Rosset C, Netto CBO, Ashton-Prolla P. TSC1 and TSC2 gene mutations and their implications for treatment in Tuberous Sclerosis Complex: a review. Genet Mol Biol. 2017;40(1):69-79.

10. Schubert-Bast S, Rosenow F, Klein KM, Reif PS, Kieslich M, Strzelczyk A The role of $\mathrm{mTOR}$ inhibitors in preventing epileptogenesis in patients with TSC: Current evidence and future perspectives. Epilepsy Behav. 2019;91:94-8

11. Shepherd C, Koepp M, Myland M, Patel K, Miglio C, Siva V, Gray E, Neary M. Understanding the health economic burden of patients with tuberous sclerosis complex (TSC) with epilepsy: a retrospective cohort study in the UK Clinical Practice Research Datalink (CPRD). BMJ Open. 2017;7(10):e015236.

12. Zöllner JP, Grau J, Rosenow F, Sauter M, Knuf M, Kurlemann G, Mayer T, Hertzberg C, Bertsche A, Immisch I, et al. Direct and indirect costs and cost-driving factors in adults with Tuberous sclerosis complex: a multicenter cohort study and a review of the literature. Orphanet J Rare Dis. 2021;16(1):250.

13. Kingswood JC, Crawford P, Johnson SR, Sampson JR, Shepherd C, Demuth D, Erhard C, Nasuti P, Patel K, Myland M, et al. The economic burden of tuberous sclerosis complex in the UK: a retrospective cohort study in the Clinical Practice Research Datalink. J Med Econ. 2016;19(11):1087-98.

14. Jansen AC, Vanclooster S, de Vries PJ, Fladrowski C, Beaure d'Augeres G, Carter T, Belousova E, Benedik MP, Cottin V, Curatolo P, et al. Burden of illness and quality of life in tuberous sclerosis complex: findings from the TOSCA study. Front Neurol. 2020;11:904.

15. Zöllner JP, Conradi N, Sauter M, Knuf M, Knake S, Kurlemann G, Mayer T, Hertzberg C, Bertsche A, Immisch I et al. Quality of life and its predictors in adults with tuberous sclerosis complex (TSC) A multicentre cohort study from Germany. Neurol Res Pract. 2021;3:35. https://doi.org/10.1186/ s42466-021-00130-3.

16. Henske EP, Jóźwiak S, Kingswood JC, Sampson JR, Thiele EA. Tuberous sclerosis complex. Nat Rev Dis Primers. 2016;2:16035.

17. Northrup H, Krueger DA. International Tuberous Sclerosis Complex Consensus G: Tuberous sclerosis complex diagnostic criteria update: recommendations of the 2012 linternational Tuberous Sclerosis Complex Consensus Conference. Pediatr Neurol. 2013;49(4):243-54.

18. Fisher RS, Cross JH, French JA, Higurashi N, Hirsch E, Jansen FE, Lagae L, Moshe SL, Peltola J, Roulet Perez E, et al. Operational classification of seizure types by the International League Against Epilepsy: Position Paper of the ILAE Commission for Classification and Terminology. Epilepsia. 2017;58(4):522-30. 
19. Scheffer IE, Berkovic S, Capovilla G, Connolly MB, French J, Guilhoto L, Hirsch E, Jain S, Mathern GW, Moshe SL, et al. ILAE classification of the epilepsies: position paper of the ILAE Commission for Classification and Terminology. Epilepsia. 2017;58(4):512-21.

20. von Elm E, Altman DG, Egger M, Pocock SJ, Gotzsche PC, Vandenbroucke JP, Initiative S. The Strengthening the Reporting of Observational Studies in Epidemiology (STROBE) statement: guidelines for reporting observational studies. PLoS Med. 2007;4(10):e296.

21. Riechmann J, Strzelczyk A, Reese JP, Boor R, Stephani U, Langner C, Neubauer BA, Oberman B, Philippi H, Rochel M, et al. Costs of epilepsy and cost-driving factors in children, adolescents, and their caregivers in Germany. Epilepsia. 2015;56(9):1388-97.

22. Strzelczyk A, Nickolay T, Bauer S, Haag A, Knake S, Oertel WH, Reif PS, Rosenow F, Reese JP, Dodel R, et al. Evaluation of health-care utilization among adult patients with epilepsy in Germany. Epilepsy Behav. 2012;23(4):451-7

23. Strzelczyk A, Schubert-Bast S, Bast T, Bettendorf U, Fiedler B, Hamer HM, Herting A, Kalski M, Kay L, Kieslich M, et al. A multicenter, matched case-control analysis comparing burden-of-illness in Dravet syndrome to refractory epilepsy and seizure remission in patients and caregivers in Germany. Epilepsia. 2019;60(8):1697-710.

24. Graf von der Schulenburg JM, Greiner W, Jost F, Klusen N, Kubin M, Leidl R, Mittendorf T, Rebscher H, Schoeffski O, Vauth C, et al. German recommendations on health economic evaluation: third and updated version of the Hanover Consensus. Value Health. 2008;11(4):539-44.

25. Willems LM, Richter S, Watermann N, Bauer S, Klein KM, Reese JP, Schöffski O, Hamer HM, Knake S, Rosenow F, et al. Trends in resource utilization and prescription of anticonvulsants for patients with active epilepsy in Germany from 2003 to 2013 - a ten-year overview. Epilepsy Behav. 2018;83:28-35.

26. Schwabe U, Paffrath D, Ludwig WD, Klauber J. Arzneiverordnungs-Report 2019. Heidelberg: Springer; 2019.

27. Bock JO, Brettschneider C, Seidl H, Bowles D, Holle R, Greiner W, König $\mathrm{HH}$. Calculation of standardised unit costs from a societal perspective for health economic evaluation. Gesundheitswesen. 2015;77(1):53-61.

28. Online-Version des EBM [http://www.kbv.de/html/online-ebm.php]. Accessed Nov 2020.

29. Pflegekasse und Pflegerecht [http://www.pflege.de/pflegekasse-pfleg erecht/pflegegrade]. Accessed Nov 2020.

30. DESTATIS Statistisches Bundesamt [http://www.destatis.de]. Accessed Nov 2020.

31. Desgagne A, Castilloux AM, Angers JF, LeLorier J. The use of the bootstrap statistical method for the pharmacoeconomic cost analysis of skewed data. Pharmacoeconomics. 1998;13(5 Pt 1):487-97.

32. Song X, Liu Z, Cappell K, Gregory C, Said Q, Prestifilippo J, Charles H, Hulbert J, Bissler J. Healthcare utilization and costs in patients with tuberous sclerosiscomplex-related renal angiomyolipoma. J Med Econ. 2017;20(4):388-94.

33. Sun P, Liu Z, Krueger D, Kohrman M. Direct medical costs for patients with tuberous sclerosis complex and surgical resection of subependymal giant cell astrocytoma: a US national cohort study. J Med Econ. 2015;18(5):349-56.

34. Strzelczyk A, Reese JP, Dodel R, Hamer HM. Cost of epilepsy: a systematic review. Pharmacoeconomics. 2008;26(6):463-76.

35. Vekeman F, Magestro M, Karner P, Duh MS, Nichols T, van Waalwijk van Doorn-Khosrovani SB, Zonnenberg BA. Kidney involvement in tuberous sclerosis complex: the impact on healthcare resource use and costs. J Med Econ. 2015;18(12):1060-70.

36. Kingswood JC, Nasuti P, Patel K, Myland M, Siva V, Gray E. The economic burden of tuberous sclerosis complex in UK patients with renal manifestations: a retrospective cohort study in the clinical practice research datalink (CPRD). J Med Econ. 2016;19(12):1116-26.

37. Kristof AS, Zhi Li P, Major P, Landry JS. Lymphangioleiomyomatosis and tuberous sclerosis complex in Quebec: prevalence and health-care utilization. Chest. 2015;148(2):444-9.
38. Skalicky AM, Rentz AM, Liu Z, Wheless JW, Pelletier CL, Dunn DW, Frost MD, Nakagawa J, Magestro M, Prestifilippo J, et al. The burden of subependymal giant cell astrocytomas associated with tuberous sclerosis complex: results of a patient and caregiver survey. J Child Neurol. 2015:30(5):563-9.

39. Wilson TA, Rodgers S, Tanweer O, Agarwal P, Lieber BA, Agarwal N, McDowell M, Devinsky O, Weiner H, Harter DH. Tuberous sclerosis health care utilization based on the national inpatient sample database: a review of 5655 hospitalizations. World Neurosurg. 2016:91:97-105.

40. Skalicky AM, Rentz AM, Liu Z, Said Q, Nakagawa JA, Frost MD, Wheless JW, Dunn DW. Economic burden, work, and school productivity in individuals with tuberous sclerosis and their families. J Med Econ. 2018;21(10):953-59.

41. Strzelczyk A, Kalski M, Bast T, Wiemer-Kruel A, Bettendorf U, Kay L, Kieslich M, Kluger G, Kurlemann G, Mayer T, et al. Burden-of-illness and cost-driving factors in Dravet syndrome patients and carers: a prospective, multicenter study from Germany. Eur J Paediatr Neurol. 2019;23(3):392-403.

42. Riechmann J, Willems LM, Boor R, Kieslich M, Knake S, Langner C, Neubauer BA, Oberman B, Philippi H, Reese JP, et al. Quality of life and correlating factors in children, adolescents with epilepsy, and their caregivers: a cross-sectional multicenter study from Germany. Seizure. 2019;69:92-8.

43. Willems LM, Watermann N, Richter S, Kay L, Hermsen AM, Knake S, Rosenow F, Strzelczyk A. Incidence, risk factors and consequences of epilepsyrelated injuries and accidents: a retrospective, single center study. Front Neurol. 2018;9:414

44. Strzelczyk A, Schubert-Bast S, Simon A, Wyatt G, Holland R, Rosenow F. Epidemiology, healthcare resource use, and mortality in patients with probable Lennox-Gastaut syndrome: a population-based study on German health insurance data. Epilepsy Behav. 2021;115:107647.

45. Strzelczyk A, Grau J, Bast T, Bertsche A, Bettendorf U, Hahn A, Hartmann $H$, Hertzberg C, Hornemann F, Immisch I, et al. Prescription patterns of antiseizure drugs in Tuberous sclerosis complex (TSC)-associated epilepsy: a multicenter cohort study from Germany and review of the literature. Expert Rev Clin Pharmacol. 2021;14(6):749-60.

46. Willems LM, Hamer HM, Knake S, Rosenow F, Reese JP, Strzelczyk A. General trends in prices and prescription patterns of anticonvulsants in Germany between 2000 and 2017: analysis of national and cohort-based data. Appl Health Econ Health Policy. 2019;17(5):707-22.

47. Chu WC, Chiang LL, Chan DC, Wong WH, Chan GC. Prevalence, mortality and healthcare economic burden of tuberous sclerosis in Hong Kong: a population-based retrospective cohort study (1995-2018). Orphanet J Rare Dis. 2020;15(1):264.

48. Betts KA, Stockl KM, Yin L, Hollenack K, Wang MJ, Yang X. Economic burden associated with tuberous sclerosis complex in patients with epilepsy. Epilepsy Behav. 2020;112:107494.

49. Hallett L, Foster T, Liu Z, Blieden M, Valentim J. Burden of disease and unmet needs in tuberous sclerosis complex with neurological manifestations: systematic review. Curr Med Res Opin. 2011;27(8):1571-83.

50. Kotulska K, Kwiatkowski DJ, Curatolo P, Weschke B, Riney K, Jansen F, Feucht M, Krsek P, Nabbout R, Jansen AC, et al. Prevention of epilepsy in infants with tuberous sclerosis complex in the EPISTOP trial. Ann Neurol. 2021;89(2):304-14.

51. Stockinger J, Strzelczyk A, Nemecek A, Cicanic M, Bösebeck F, Brandt C, Hamer H, Intravooth T, Steinhoff BJ. Everolimus in adult tuberous sclerosis complex patients with epilepsy: Too late for success? A retrospective study. Epilepsia. 2021;62(3):785-94.

\section{Publisher's Note}

Springer Nature remains neutral with regard to jurisdictional claims in published maps and institutional affiliations. 